\title{
Vem Aprender: Objetos de Aprendizagem para o ensino de Estatística
}

\author{
Gustavo de Oliveira Andrade ${ }^{1}$, Chang Kuo Rodrigues ${ }^{2}$ \\ ${ }^{1}$ Instituto Federal de Educação, Ciência e Tecnologia do Espírito Santo (IFES) \\ Campus Barra de São Francisco - Espírito Santo - ES - Brasil \\ ${ }^{2}$ Programa de Pós-Graduação em Ensino de Ciências - Universidade do Grande Rio - \\ UNIGRANRIO \\ Campus Duque de Caxias - Rio de Janeiro - RJ - Brasil \\ gustavo.andrade@ifes.edu.br; changkuockr@gmail.com
}

\begin{abstract}
More and more teachers have sought to innovate educational practices related to teaching and learning. The use of learning objects in the learning process is one of those innovations. In this article, we present the Learning Object "Come Learn: Education Statistics" in order to meet the mathematical discipline, in particular, the Statistical content. On that occasion, it was possible to make a literature review on the $O A$ and present its development following all stages of interaction INTERA methodology. Validated and tested by a group of middle and high school students, the "Come Learn" presented learning signs throughout the application and implementation of the analysis, since through the stimuli moved by interactive content, the students could understand the concepts statistical.
\end{abstract}

Keywords: Learning Objects. Mathematics Education. Statistics Education.

Resumo. Cada vez mais os professores têm buscado inovar as práticas educativas relacionadas ao processo de ensino e de aprendizagem. A utilização de Objetos de Aprendizagem nas práticas pedagógicas é uma dessas inovações. Neste artigo, apresentamos o Objeto de Aprendizagem "Vem Aprender: Educação Estatística" com vistas a atender a disciplina de matemática, em especial, o conteúdo de Estatística, o que confirma com o objetivo da pesquisa que é verificar as potencialidades dos Objetos de Aprendizagem nas tarefas de estatísticas na Educação Básica. $\mathrm{Na}$ oportunidade, foi possivel fazer uma revisão da literatura sobre os $O A$ e apresentar o seu desenvolvimento seguindo todas as etapas da metodologia INTERA. Validado e testado por um grupo de alunos do ensino fundamental e médio, o "Vem Aprender" apresentou sinais de aprendizagem ao longo da aplicação e realização da análise, uma vez que por meio dos estímulos movidos pelos conteúdos interativos, os alunos puderam compreender os conceitos de estatística.

Palavras-chave: Objetos de Aprendizagem. Educação Matemática. Educação Estatística. 
V Congresso Brasileiro de Informática na Educação (CBIE 2016)

Anais do XXII Workshop de Informática na Escola (WIE 2016)

\section{Introdução}

Atualmente, a Educação vem passando por muitas transformações e, com isso, os recursos tecnológicos começaram a proporcionar novas possibilidades de socialização e de aprendizado, permitindo melhores condições de acesso a ela. Com o crescimento dessa cultura, o processo de ensino e de aprendizagem vem se tornando a cada dia mais dinâmico.

Em busca de um ensino mais reflexivo, muitos professores e instituições de ensino têm recorrido a inovações tecnológicas como o caso dos Objetos de Aprendizagem (OA), cujo investimento está cada vez mais voltado para os recursos provenientes de internet. Um dos motivos para essa mudança seria a busca por novos métodos que possam proporcionar uma aprendizagem mais eficaz para o aluno.

Os Objetos de Aprendizagem (OA), assim designados, são todos os recursos que amparam o processo de ensino. São identificados por meio de recursos digitais como vídeos, imagens, áudios, textos, jogos entre outros, os quais podem estar, ou não, agrupados em uma única aplicação. Logo, aplicar os Objetos de Aprendizagem é transformar uma prática pedagógica voltada para interatividade, desenvolvimento de competências e estímulo de interesse aos alunos.

Este artigo justifica-se pela importância em conhecer os Objetos de Aprendizagem e tem como objetivo verificar suas potencialidades no tocante à aplicabilidade das tarefas estatísticas na Educação Básica, ao estarem disponíveis no Portal "Vem Aprender: Educação Estatística". O artigo foi dividido em sete partes, sendo que a primeira é introdutória e tem como objetivo situar o leitor sobre o tema; na segunda parte, apresenta-se a metodologia científica adotada no trabalho e no desenvolvimento do OA - Vem Aprender; a terceira parte tem a fundamentação teórica sobre Objetos de Aprendizagem; já na quarta parte, apresentamos alguns trabalhos relacionados à temática; o "Vem Aprender: Educação Estatística" com vistas a atender o ensino de Estatística, será apresentado na quinta parte; na sexta parte, apresentamos a validação do Objeto por meio de uma análise de dados realizada com alunos do ensino fundamental e médio e, por fim, as considerações finais na sétima parte, seguida das referências.

\section{Metodologia do trabalho}

Os procedimentos metodológicos iniciam-se pela revisão dos principais conceitos teóricos necessários para a compreensão do modelo e desenvolvimento do Objeto de Aprendizagem, sendo, portanto, esta pesquisa de natureza bibliográfica. [Richardson, 2010]. A elaboração e a construção do OA "Vem Aprender" estão pautadas na metodologia INTERA [Inteligência, Tecnologias Educacionais e Recursos Acessíveis] [Braga; Pimentel; Dotta, 2013]. A fim de que possamos compreender os elementos primordiais para a contextualização e o esboço do artigo, será necessário fundamentar os OA e suas características pela pesquisa bibliográfica, além de construí-lo pela metodologia INTERA e validá-lo por meio da pesquisa experimental [Gil, 2010] amparada nos aspectos éticos, conforme a resolução 196/96 do Conselho Nacional de Ética em Pesquisa e que foi submetida ao Comitê de Ética em Pesquisa da UNIGRANRIO sob o número: 39362714.1.0000.5283 e aprovado, juntamente com a pesquisa quantitativa [Richardson, 2010], já que o presente trabalho é oriundo da dissertação de mestrado de Andrade [2015]. 
V Congresso Brasileiro de Informática na Educação (CBIE 2016)

Anais do XXII Workshop de Informática na Escola (WIE 2016)

\section{Fundamentação teórica}

A Matemática, disciplina presente em quase todos os níveis da Educação, na maioria das vezes, é a causa de um maior índice de reprovação e, consequentemente, provoca o desinteresse por parte dos educandos por essa área do conhecimento. O conteúdo de Estatística, geralmente ministrado no segundo ano do Ensino Médio, de modo um pouco mais detalhado, "é uma parte da Matemática Aplicada que fornece métodos para a coleta, organização, descrição, análise e interpretação de dados e para a utilização dos mesmos na tomada de decisões" [Crespo, 1995, p. 13].

Os Objetos de Aprendizagem, por sua vez, são todos os recursos que auxiliam o processo de ensino e que podem ser reutilizados em diversos contextos. Esses objetos são identificados por meio de "recursos digitais, tais como vídeos, imagens, áudios, textos gráficos, tabelas, mapas, jogos, simulações, animações e infográficos, os quais podem ser utilizados isoladamente ou agrupados em um único aplicativo" [Fiscarelli; Fiscarelli, 2011, p. 188].

Reforçando essa definição, Wiley [2000, p. 4] esclarece que Objeto de Aprendizagem é "qualquer recurso digital que possa ser reutilizado para apoiar a aprendizagem". Ainda segundo o mesmo autor, a principal ideia do OA é permitir aos designers instrucionais a construção de pequenos componentes, que podem ser reutilizados diversas vezes, em vários contextos de aprendizagem. Por outro lado, Filatro [2008] destaca que os OA:

[...] são 'pedaços de conhecimento' autocontidos identificados por descritores que trazem dados sobre autores, palavras-chave, assunto, versão, localização, regras de uso e propriedade intelectual, requisitos técnicos, tipo de mídia utilizada e nível de interatividade, entre outros [...]. Seus elementos internos são organizados por meio de um mecanismo de empacotamento de conteúdos [do inglês, content packaging], que representa a estruturação dos conteúdos e o conjunto de regras para sequenciar a sua apresentação. [Filatro, 2008, p. 54]

Os OA auxiliam o processo de ensino pelo fato de integrar os recursos digitais que dão suporte à aprendizagem, ou seja, permitem que o conteúdo seja dividido em pequenos módulos, colaborando, assim, para a aprendizagem. "O grande papel de um objeto de aprendizagem é tornar o processo de aprendizagem mais lúdico e interativo, o que facilitaria a compreensão dos fenômenos estudados" [Fiscarelli; Fiscarelli, 2011, p. $188]$.

\section{Trabalhos relacionados}

Com o intuito de manter contato com as mais recentes publicações sobre o tema, fez-se necessário uma busca na base de dados da CAPES [Coordenação de Aperfeiçoamento de Pessoal de Nível Superior] e dos anais do CBIE [Congresso Brasileiro de Informática na Educação], a partir dos seguintes descritores: Objeto de Aprendizagem, Ensino da matemática, Ensino de Estatística.

Após executadas as buscas com a combinação dos termos, os artigos selecionados foram lidos e analisados. No trabalho de Santos [2011], o pesquisador descreve a importância em desenvolver um Objeto de Aprendizagem com intuito de 
dinamizar o processo de ensino de conceitos de probabilidade. Santos [2011] apoiou-se na teoria da Aprendizagem Significativa de Ausubel e na Construcionista de Papert como referenciais teóricos para sua dissertação. A análise foi realizada com uma turma de $3^{\text {a }}$ série de Ensino Médio de uma Escola Municipal do interior de Pernambuco, quando foi possível apontar algumas mudanças significativas na comunicação e na interação entre os alunos, ocasionando assim, uma melhoria significativa no processo de ensino e de aprendizagem. O autor acredita que os $\mathrm{OA}$ oferecem condições essenciais aos estudantes para participar da construção de seu próprio conhecimento além de favorecer uma melhor aquisição de conhecimentos, capacidades e habilidades sobre probabilidade.

Já no trabalho de Kenne et al [2015], os recursos digitais de aprendizagem foram desenvolvidos para atender as especificidades que envolvem operações matemáticas básicas. O ViLaGa, blog, desenvolvido pelo grupo para apoiar as atividades, tem como meta realizar todo o gerenciamento de entradas e saídas de mercadorias por meio da ação de comprar e vender. Nota-se a participação e o envolvimento dos alunos durante todo o processo, fazendo com que a colaboração e cooperação caminhassem juntas. Por fim, esta ferramenta utilizada possibilitou novas oportunidades de aprendizagem por meio de trocas e compartilhamento de conhecimentos.

Santos e Silva Jr. [2015] apresentam em seu trabalho um jogo de tabuleiro intitulado "Conquistando com o Resto", cujo foco é auxiliar a aprendizagem de divisão de forma lúdica. O jogo passou por diversas avaliações, dentre elas, os aspectos de usabilidade além dos pedagógicos. Dez alunos avaliaram o jogo, além de professores e pesquisadores da área. Constatou-se, por meio dessa análise, que o "Conquistando com o Resto" foi qualificado de forma positiva por todos os envolvidos e atendeu os objetivos traçados.

\section{OA: "Vem Aprender: Educação Estatística"}

O Objeto de Aprendizagem "Vem Aprender: Educação Estatística" é um portal, interativo, disponível de forma gratuita na internet e visa apoiar a aprendizagem do ensino da Matemática, em especial, do conteúdo de Estatística para crianças, jovens e adultos. Diversos conceitos são abordados, tais como: fases do método estatístico, curiosidades, materiais complementares, podcast, jogos, vídeos, exercícios, apostilas, resenhas, notas, dentre outros.

Ao projetar o "Vem Aprender", foi preciso reunir informações de seu públicoalvo, que, em sua maioria, é de usuários que buscam, além do saber, uma interface rica, interativa e atraente. O padrão de design utilizado para o desenvolvimento do Objeto de Aprendizagem foi de $1024 \times 627$ pixels. O design é o elemento base que liga todas as etapas do processo de desenvolvimento, assim, o design utilizado para a concepção do projeto concentrou-se em atender os padrões estabelecidos da web [W3C $\mathrm{C}^{1}$, além de possibilitar uma navegação eficiente, atrativa e interativa para o usuário.

O "Vem Aprender" é capaz de ser executado por quaisquer navegadores $\mathrm{Web}$ sem restrição, sendo necessária apenas a ativação do plug-in Flash. O portal ainda apresenta telas apropriadas para o usuário; menus que permitem ao usuário, por um simples clique com o mouse, escolher a opção desejada; botões de saída e retorno à tela

\footnotetext{
${ }^{1} \mathrm{O}$ World Wide Web Consortium é a principal organização de padronização da World Wide Web.
} 
V Congresso Brasileiro de Informática na Educação (CBIE 2016)

Anais do XXII Workshop de Informática na Escola (WIE 2016)

inicial; cenários que reflitam sobre os conceitos apresentados; usabilidade, dentre outros.

O esboço do "Vem Aprender", Figura 1, apresenta, na tela inicial, a nomeação do OA, bem como as opções pelas quais o usuário poderá acessar. Nessa tela, o usuário poderá escolher a opção desejada, em seguida, o mesmo será direcionado para a página/opção/item correspondente.

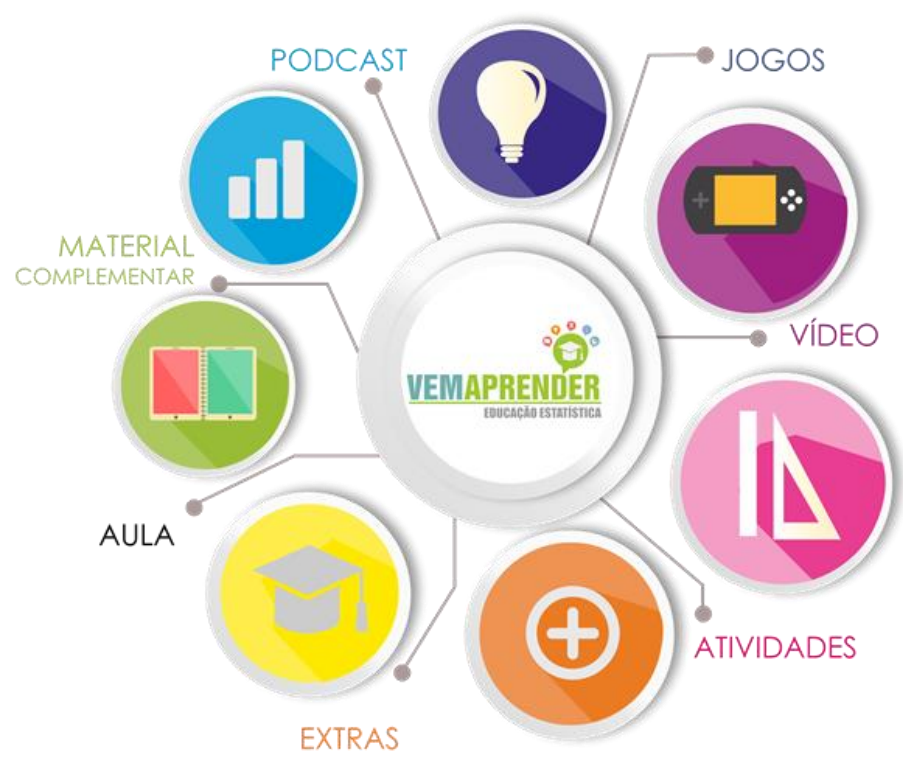

Figura 1 - Tela inicial do "Vem Aprender" Fonte: Dados da pesquisa

A seguir, apresentamos a Figura 2 para ilustrar um dos recursos disponíveis no "Vem Aprender", no intuito de ilustrar o caráter visual e interativo desse OA.

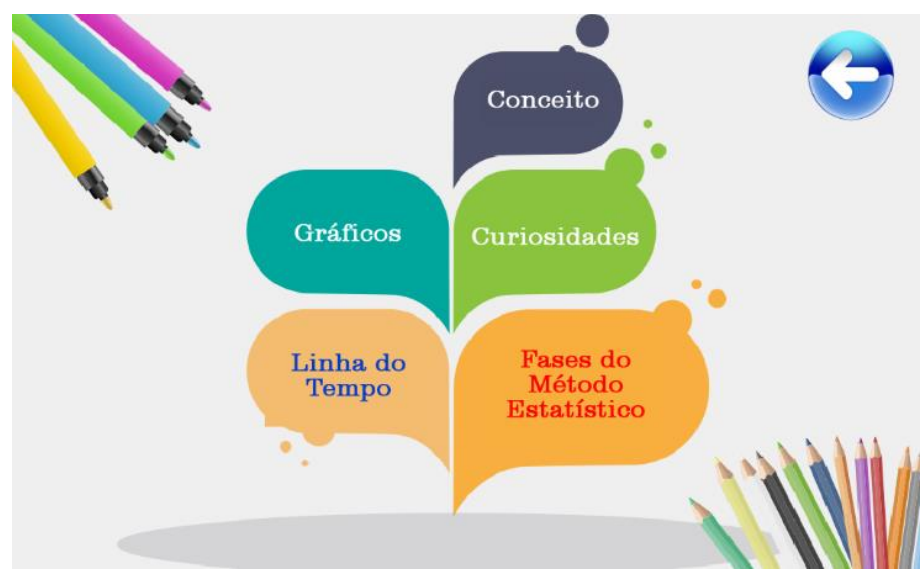

Figura 2 - Vem Aprender: Menu "Aula"

Fonte: Dados da pesquisa 
V Congresso Brasileiro de Informática na Educação (CBIE 2016)

Anais do XXII Workshop de Informática na Escola (WIE 2016)

Na Figura 2, é apresentada a ferramenta menu, estimulando a curiosidade do usuário diante das opções apresentadas, o que corrobora a interatividade do OA com o usuário.

\section{Análise dos resultados - Vem Aprender: Educação Estatística}

O "Vem Aprender" foi validado por dezesseis alunos do Ensino Fundamental e Médio durante o período de 02 de julho de 2015 a 08 de julho de 2015 de uma escola estadual, em Leopoldina, Minas Gerais (MG).

Para o levantamento das informações, foi aplicado um questionário misto com perguntas discursivas e fechadas. A observação in loco das atividades nos laboratórios de informática foi importante para a realização desta pesquisa. A ferramenta adotada na coleta de dados foi o Google Docs, por ser bem apropriada para a interatividade e colaboração.

Diante da aplicação do questionário, foi possível constatar que apenas 37,5\% dos alunos participantes têm experiência na utilização dos recursos de informática há mais de três anos, enquanto os demais têm experiência inferior a três anos. Os dados também mostram que $12,5 \%$ dos alunos têm experiência de um a dois anos e $18,8 \%$, de dois a três anos. Esses dados mostram que os alunos pesquisados possuem pouca experiência com a utilização dos recursos de informática, pois 31,3\% têm de até um ano.

Apesar de a utilização dos computadores ter se popularizado bastante nas últimas décadas, é perceptível que o aprendizado sobre estatística não foi muito bem introduzido ao universo desses alunos. Vale destacar que, conforme Costa [2007 apud Santos; Alves, 2011, p.5] "o material à disposição em sala de aula para que o professor do Ensino Fundamental e Médio possa trabalhar os conteúdos de Estatística, na maioria das vezes, restringe-se ao livro didático de Matemática, que contempla em seu interior alguns tópicos para desenvolvimento de tal disciplina." Logo, é necessário ir ao encontro de outros meios para que a aprendizagem não fique preconizada apenas nos livros didáticos. Com base nesta pesquisa, apenas $25 \%$ dos alunos tiveram contato com essa disciplina no Ensino Fundamental e no Médio. Enquanto 75\% não estudaram estatística durante sua vida acadêmica. Essa diferença mostra que a utilização dos Objetos de Aprendizagem para o ensino desse conteúdo pode contribuir para que os alunos conheçam a disciplina e apliquem-na em seu dia a dia, se necessário.

Em relação à avaliação da aprendizagem, não ocorreram muitas dificuldades quanto a realização de atividades por meio dos Objetos de Aprendizagem. Uma questão levantada no processo foi a demora no carregamento da página e apenas um pequeno problema técnico na seção de apostilas. Porém, entre os alunos que fizeram uso do Objeto de Aprendizagem, não foram observadas dificuldades quanto à sua utilização.

Ao serem questionados se a atividade precisava fornecer mais informações, como textos e demais instruções, 98\% responderam que não existia necessidade de muitas informações, pois o programa oferece os subsídios adequados para o manuseio do OA. Apenas $2 \%$ dos alunos acharam que o programa deveria conter um número maior de informações e até mais atividades que envolvessem a estatística. 
Assim, para o aprimoramento dos Objetos, foi pedida a participação desses alunos, visando à sua melhoria, por meio de sugestões. Nesse caso, a maioria dos alunos entrevistados não quis dar sugestões, embora, entre os alunos que opinaram, houvesse sugestões diversificadas, como, por exemplo, falar mais da matemática em detrimento da história da estatística, fazer o acréscimo de jogos, de atividades infantis e de um sistema de pontuação, para que, a partir do momento em que o aluno acerte, seja levado a uma próxima etapa.

Dentre os recursos disponibilizados pela atividade, os exercícios apresentaram um percentual de $68,8 \%$ em relação à sua importância junto ao Objeto. Em seguida, os materiais em PDF tiveram 53,3\% dos votos e os textos obtiveram 50\%, enquanto vídeo e animação, 43,8\%. Os dados mostraram que os alunos, além de demonstrarem interesse na animação, deram, também, importância aos conceitos estatísticos.

Em relação à opinião do que o aluno mais gostou no Objeto, as respostas foram bastante diversificadas, alguns gostaram dos jogos e suas animações, outros, das atividades e, também, dos slides e vídeos. O que se pode observar foi que os alunos, em algum momento, davam importância à interatividade da atividade, ou seja, ao próprio objetivo do OA. Quando perguntado sobre o que menos gostaram no Objeto, as opiniões também foram bastante diversificadas. Uma das maiores reclamações foi em relação aos vídeos, pois o carregamento do site se encontrava lento, dificultando um pouco o acesso aos links.

Em relação às sequências dos tópicos do Objeto, 93,8\% dos alunos responderam que "sim", estavam coerentes, enquanto apenas 6,3\% deles disseram "não". Já em relação à avaliação técnica, $83,3 \%$ dos alunos responderam concordar que o "Vem Aprender" é um programa fácil de usar. Dentre os que concordaram plenamente com sua eficiência, chegou-se a $12,5 \%$ e apenas $6,3 \%$ não expressaram concordância e também não se manifestaram sobre a questão.

Ao se tratar da clareza das instruções expressas no Objeto, foi possível constatar que $62,5 \%$ dos alunos concordaram que o objetivo apresentava clareza em sua usabilidade; $12,5 \%$ nem concordaram e nem discordaram; e, por fim, 6,3\% dos entrevistados discordaram plenamente, enquanto outros $6,3 \%$ concordaram plenamente, ou não quiseram responder a questão. Nesse aspecto, conclui-se que os Objetos de Aprendizagem, por se apresentarem de forma clara e concisa, podem proporcionar grandes chances na aprendizagem.

$\mathrm{O}$ visual que buscávamos dar ao $\mathrm{OA}$ era o mais interativo possível, por isso apresenta uma arquitetura lúdica e colorida. Para Heidrich et al [2010, p.5] ao desenvolver um objeto "deve-se priorizar o uso de linguagem compatível com a criança, para facilitar a compreensão do que está sendo informado e para que a informação não necessite ser recodificada". E, corroborando esta afirmativa, $62,5 \%$ concordaram serem as páginas bastante atraentes, $31,3 \%$ aprovaram completamente o visual do Objeto e apenas $6,3 \%$ não quiseram opinar. A aprovação do ambiente interativo por mais de $50 \%$ dos alunos vem mostrar que, embora os Objetos ainda precisem de alguns ajustes, seu visual interativo chama bastante a atenção do aluno.

A interatividade é a marca registrada dos Objetos de Aprendizagem, pois eles são feitos para que o aluno aprenda de maneira mais lúdica. Na visão de Heidrich et al [2010, p.5], a interatividade deve "ser apropriada, adequada e relevante para facilitar a aquisição do conhecimento ou o desenvolvimento de novas habilidades e a 
compreensão", de forma que a troca de informações aconteça. Em se tratando do "Vem Aprender", 62,5\% dos alunos responderam concordarem com a ludicidade do Objeto, $31,3 \%$ concordaram plenamente e $6,3 \%$ não quiseram opinar sobre o assunto. A ludicidade é um recurso que possibilita ao aluno aprender de maneira mais prazerosa e consistente.

Quando perguntados sobre a facilidade de navegação e consistência, ao longo de todo o portal, $43,8 \%$ dos alunos disseram que concordam com essa afirmação, enquanto $18,8 \%$ discordaram, outros 25\% nem concordaram e nem discordaram e 6,3\% concordaram plenamente [outros não quiseram opinar]. Como o Objeto ainda se encontrava em período de teste, foram observadas algumas dificuldades em relação à navegação, como, por exemplo, a lentidão da abertura dos links na página.

Em relação à existência de harmonia entre cores, fontes, animações e vinhetas, constatou-se que 56,3\% dos alunos concordaram com os benefícios desse recurso. Outros 37,5\% concordaram completamente e apenas $6,3 \%$ dos alunos não quiseram se posicionar sobre o assunto. Essa harmonia possibilita ao OA interatividade a motivação, pois esses recursos são essenciais para uma apresentação harmônica e dinâmica, além de "facilitar a aquisição de novos conhecimentos e também interferir no processo cognitivo de modo a auxiliar no desenvolvimento das funções" Heidrich et al [2010, p.5]

Em relação ao conteúdo, $87,5 \%$ disseram ser claro e conciso, $6,3 \%$ não concordaram e nem discordaram e outros $6,3 \%$ não responderam a essa questão. A relevância dos conteúdos também foi uma questão que se destacou, assim, 56,3\% dos entrevistados concordaram com sua eficácia. Outros $12,5 \%$ concordaram plenamente e $25 \%$ não concordaram e nem discordaram.

Quando perguntado se os conteúdos apresentam conceitos básicos, 81,3\% dos alunos concordaram com esses conceitos; os outros 6,3\% não concordaram e nem discordaram, concordaram plenamente ou não quiseram responder a essas questões. Os conceitos básicos apresentados nos $\mathrm{OA}$ são meios que buscam facilitar a interação do aluno com o Objeto e, também, com os conceitos estatísticos.

Ao perguntar se a quantidade do conteúdo é apropriada ao material, $50 \%$ dos alunos concordaram que sim, é apropriado, $25 \%$ não concordaram e nem discordaram e $12,5 \%$ concordaram plenamente com a disposição do material. Porém, os que possuem opinião contrária somaram apenas $6,3 \%$.

Em relação ao que o aluno aprendeu com os Objetos de Aprendizagem, ao perguntar se o aluno acha que o OA trouxe de benefício para sua aprendizagem, a maior parte deles respondeu que os auxiliaram na compreensão de conceitos sobre moda e mediana. Para apenas um aluno o conteúdo não trouxe benefícios e outros não tiveram tempo de ler, portanto, nessa questão, as opiniões foram mais diversificadas. Nunes [2006] ressalta outros benefícios proporcionados pelo uso de OA de forma que os alunos possam "relacionam novos conhecimentos com os que já sabiam, fazem e testam hipóteses, pensam onde aplicar o que estão aprendendo, expressam-se por meio de várias linguagens, aprendem novos métodos, novos conceitos, aprendem a ser críticos sobre os limites de aplicação dos novos conhecimentos, etc".

Em relação ao aprendizado, foi pedido aos alunos que, com suas palavras, definissem moda, média e mediana. Mais da metade dos alunos conseguiu definir esses 
três conceitos, embora alguns tenham dito que nunca estudaram tal conteúdo na escola, ou por não terem lido, ou por falta de tempo para ler tudo.

Quanto à importância da estatística para o aluno e, até mesmo, para sua vida cotidiana, a maioria dos alunos respondeu que ela é importante e que auxilia na realização de cálculos importantes. Um aluno declarou que o conteúdo não é relevante para seu aprendizado e outro, que ainda não sabe por que não aprendeu ainda. $O$ aprendizado da estatística, segundo as respostas desta questão, auxilia no aprendizado dos alunos.

Quanto ao pedido de um exemplo de utilização da estatística em nosso dia a dia, as respostas foram bastante variadas, como, por exemplo, alguns alunos falaram sobre sua utilização em escolas, comércios, postos de gasolina, médias finais em disciplina escolares. Embora a estatística não seja uma disciplina muito comum no ensino fundamental e médio, ela é muito utilizada no dia a dia, apesar de muitos desses alunos nunca tivessem percebido isso.

\section{Considerações finais}

A artigo mostrou que os alunos estão cientes da importância dos OA para o estudo da estatística, muito embora esse conteúdo deveria ter sido mais explorado no ensino fundamental e no ensino médio, ou seja, durante sua vida na educação básica.

A pesquisa também revelou a facilidade de acesso ao $\mathrm{OA}$, cuja eficiência é atrelada à sua acessibilidade. Foram criados recursos que facilitassem o manuseio dos OA por parte dos alunos, como, por exemplo, as mídias e seu layout, atrelados ao conteúdo da estatística.

Já em relação ao layout e também ao design utilizado no OA, foi possível afirmar que proporcionaram ao projeto muitos benefícios, tanto em termos de aprendizado, quanto em termos estéticos, pois constituiu-se uma ferramenta de atração, possibilitando ao aluno estímulos para seu manuseio e aprendizado do conteúdo.

Sinais de aprendizagem foram identificados ao longo da aplicação e realização da análise, uma vez que por meio dos estímulos movido pelos conteúdos interativos do "Vem Aprender", os alunos puderam compreender os conceitos de Estatística.

Enfim, a escolha pelo uso dos Objetos de Aprendizagem remete o aprendizado a um novo modelo educacional, transformando-o em algo diferente da usual aula expositiva, além de ser dinâmico e interativo. Essa transformação tem feito com que os alunos se tornem mais participativos junto ao processo de aprender, visto que são vários os estilos de aprendizagem vivenciados por eles.

\section{Referências}

Andrade, G. O. [2015]. A potencialidade dos objetos de aprendizagem no ensino da matemática. Dissertação de Mestrado em Ensino de Ciências da UNIGRANRIO, 2015.

Braga, J. C., Pimentel, E., Dotta, S. [2013], Metodologia INTERA para o desenvolvimento de Objetos de Aprendizagem. XXIV Simpósio Brasileiro de Informática na Educação. Anais... Campinas.

Crespo, A. A. [1995]. Estatística fácil. 13. ed. São Paulo: Saraiva. 
V Congresso Brasileiro de Informática na Educação (CBIE 2016)

Anais do XXII Workshop de Informática na Escola (WIE 2016)

Filatro, A. [2008]. Design Instrucional na prática. São Paulo: Pearson.

Fiscarelli, R. B. O. Fiscarelli, S. H. [2011], Tecnologia na educação: dos objetos reais aos objetos virtuais. In: Monteiro, S. A. I., Ribeiro, R., Lemes, S. S., Muzzeti, L.R. [org]. Educações na contemporaneidade: Reflexão e pesquisa. São Carlos: Pedro \& João.

Gil, A. C. [2010]. Como elaborar projetos de pesquisa. 5. ed. São Paulo: Atlas.

Gladcheff, A., P. Zuffi, E. M. Silva, M., D. [2011]. Um Instrumento para Avaliação da Qualidade de Softwares Educacionais de Matemática para o Ensino Fundamental. In: Anais... XVII Workshop de Informática na Escola [WIE], Alagoas.

Heidrich, R. et al, [2010]. Design Centrado no Usuário para Objetos de Aprendizagem Inclusivos. In: Anais... SBIE 2010.

Kenne, K. C. O. et al. [2015]. Professores e Estudantes trabalhando em Equipe na Escola - Matemática em uma arquitetura simulada no Ensino Fundamental. In: Anais... Workshops do IV Congresso Brasileiro de Informática na Educação, Alagoas.

Nunes, C. [2006]. Objetos de aprendizagem a serviço do professor. Disponível em: $<$ http://www.microsoft.com/brasil/educacao/parceiro/objeto_texto.mspx $>$ Acesso em: 11 mai. 2015.

Richardson, R. J. [2010]. Pesquisa Social: Métodos e Técnicas. São Paulo: Atlas.

Santos, R. J.; Alves, W. M. [2011], Uma abordagem do ensino de Estatística no Ensino Fundamental. In: Anais... XIII Conferência Interamericana de Educação Matemática. Disponível em:

http://www.gente.eti.br/lematec/CDS/XIIICIAEM/artigos/1076.pd> Acesso em: 17 ago. 2016.

Santos, W. O.; Silva Jr., C. S. [2015], Pesquisa, Desenvolvimento e Avaliação de um Jogo para o Ensino de Matemática, Baseado no Processo de Virtualização de Jogos. In: Anais... Workshops do IV Congresso Brasileiro de Informática na Educação, Alagoas. Disponível em: $<$ http://www.brie.org/pub/index.php/wcbie/article/view/5941/4169> Acesso em: 12 dez. 2015.

Santos, J. J. A. [2011]. Desenvolvimento de um Objeto de Aprendizagem para o ensino de conceitos de Probabilidade. Dissertação de Mestrado em Ensino de Ciências e Matemática da UEPB, 2011.

Wiley, D. A. [2000]. Connecting learning objects to instructional design theory: a definition, a metaphor, and a taxonomy. 2000. Disponível em: $<$ http://www.reusability.org/read/chapters/wiley.doc >. Acesso em: 10 out. 2014. 